University of Nebraska - Lincoln

DigitalCommons@University of Nebraska - Lincoln

\title{
Input-Output and Hybrid Techniques for Real-Time Prediction of Delay and Maximum Queue Length at Signalized Intersections
}

\author{
Anuj Sharma \\ University of Nebraska - Lincoln, anujs@iastate.edu \\ Darcy M. Bullock \\ Purdue University \\ James A. Bonneson \\ Texas A \& M University - College Station
}

Follow this and additional works at: https://digitalcommons.unl.edu/civilengfacpub

Part of the Civil Engineering Commons

Sharma, Anuj; Bullock, Darcy M.; and Bonneson, James A., "Input-Output and Hybrid Techniques for RealTime Prediction of Delay and Maximum Queue Length at Signalized Intersections" (2007). Civil Engineering Faculty Publications. 17.

https://digitalcommons.unl.edu/civilengfacpub/17

This Article is brought to you for free and open access by the Civil Engineering at DigitalCommons@University of Nebraska - Lincoln. It has been accepted for inclusion in Civil Engineering Faculty Publications by an authorized administrator of DigitalCommons@University of Nebraska - Lincoln. 


\title{
Input-Output and Hybrid Techniques for Real-Time Prediction of Delay and Maximum Queue Length at Signalized Intersections
}

\author{
Anuj Sharma, Darcy M. Bullock and James A. Bonneson
Sharma: Department of Civil Engineering, University of Nebraska, Lincoln, NE; asharma3@unl.edu
Bullock: School of Civil Engineering, Purdue University, West Lafayette, IN
Bonneson: Texas Transportation Institute, Texas A\&M University System, College Station, TX

Vehicle delay and queue length are quantitative measures of intersection performance. The technological advancement in the field of vehicle sensors and traffic controllers has reached a point where it has enabled efficient measurement of these performance measures. Two techniques are presented for real-time measurement of vehicle delay and queue length at a signalized Intersection, and these automated delay and queue estimates are compared with manually ground-truthed measurement. These techniques were evaluated at an instrumented intersection in Noblesville, Indiana. The root-mean-square error by both techniques was below 0.7 veh-s for-estimation of average delay and less than 0.15 vehicle for estimation of average maximum queue length, both on a cycle-by-cycle basis.

Vehicular delay and queue length are quantitative measures for evaluating performance of a signalized intersection. Numerous methods have been proposed in the past literature (1-6) for measuring intersection delay both manually and automatically. There is a trade-off between accuracy and cost in using these measures. In the recent past, cost was the prohibiting factor for implementing precise delay estimation methods in real time. Accurate measurement of vehicle delay and queue length is now economically feasible with the technological advancement in the field of vehicular sensors and traffic controllers.

Two techniques for vehicle delay and queue length measurements are proposed and evaluated. These two techniques can be used for the, estimation of delay and maximum queue length at signalized intersections in real time. This information is important for both the users of the intersection and the traffic engineer. The traffic engineer can use the information as a measure of effectiveness for the operation of the intersection. The real-time delay and average queue length information can be used by commuters to estimate their travel time and choose a travel route.

\section{DEFINITION OF DELAY}

Total delay is defined as the difference between the actual travel time across the facility and the desired travel time absent any intervening factors (7). In practice, there are numerous nuances of delay that have slightly different measurement boundary conditions. The following three types of delay are frequently used by engineers to assess intersection performance:

-Stopped delay: delay incurred when a vehicle is at a complete stop;

- Approach delay: delay incurred due to deceleration and stop time and acceleration until the vehicle crosses the stop bar; and

- Control delay: delay incurred due to deceleration, stop time, and acceleration until the vehicle attains the desired travel speed.

These three types of delay are illustrated in Figure 1. The 1997 update of the Highway Capacity Manual proposed the use of control delay for level-of-service determination at a signalized intersection. Small correction factors can be used to convert approach delay to control delay (3). A brief overview of the techniques used in this study for real-time estimation of approach delay is given next.

\section{OVERVIEW OF TECHNIQUES}

Figure 2 shows the two proposed real-time performance measurement algorithms for estimating approach delay and maximum queue length: the input-output model (Figure 2a) and the hybrid model (Figure 2b). The inputoutput technique uses advance detector actuations, phase change data, and parametric data (saturation headway, storage capacity, etc.) as model inputs. The advance detector actuations are used to track arrivals at the intersection approach over time. The phase change and saturation headway data are used to estimate the number of departures from the stop bar over time. These two flow profiles are combined to estimate the queue accumulation on the intersection approach. Once queue growth begins, the number of vehicles in queue at any given time represents the approach queue length. The time in queue is used to estimate the delay.

The hybrid technique uses advance detector actuations, stop bar detector actuations, phase change data, and parametric data (e.g., storage capacity) as model in- 


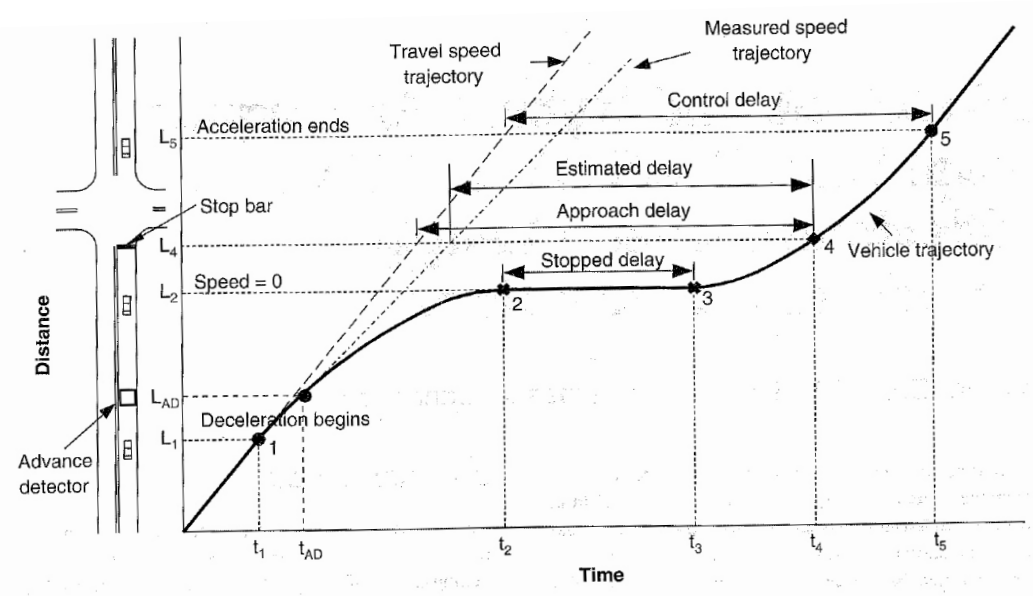

FIGURE 1 Graphical representation of different nuences of delay used by traffic engineers.

puts. The advance detector actuations are used in a manner similar to the input-output technique. The stop bar detector actuations are used, with the phase change data, to measure the number of departures from the stop bar over time. As with the input-output technique, these two flow profiles are combined to determine if there is a queue accumulation on the intersection approach and to estimate queue length and delay.

In contrast to the input-output technique, the hybrid technique requires additional detection at the stop bar. The stop bar detector can use the vehicle signature identification technique available from inductive loop detectors (ILDs) to count the number of departures. In this study, ILD vehicle signature identification techniques were used $(8,9)$ to count vehicles crossing the stop bar. The stop bar count detection provides real-time information about the departure rate. In contrast, this rate is a simple parametric input in the input-output technique. The real-time information about the departure rate is intended to make the hybrid technique more accurate than the input-output technique, particularly during inclement weather when the saturation flow rate decreases. For both techniques, delay and maximum queue length are estimated once for each signal cycle. The techniques were developed on the basis of the assumption that vehicles do not change lanes after they cross the advance detectors, The first-in-first-out (FIFO) principle (i.e., the first vehicle to enter the queue departs first) is also assumed to hold for vehicles in queue on the intersection approach.

The research project evaluated several options such as bus probes and platoon detection, traffic flow characteristics, and spot speed for running-time measurement. These two techniques emerged as two of the strongest candidates in terms of technological and economic feasibility for measuring queue length and delay at the signalized intersection. The reuse of an existing set of advance detectors (present at several high-speed intersections) makes these techniques economically viable.

\section{Estimation of Arrival Profile}

Figure $3 \mathrm{a}$ and $\mathrm{b}$ show example arrival flow profiles for the input-output and hybrid techniques, respectively. This profile represents the count of vehicles measured at the advance detector. The stair-stepped nature of the profile reflects the arrival of individual vehicles to the detector at the corresponding time. For example, in Figure $3 \mathrm{a}$, the first arrival occurs at time $t=2.0 \mathrm{~s}$; the second arrival occurs at time $t=16 \mathrm{~s}$; and so on until a sixth vehicle arrives at time $t=55 \mathrm{~s}$.

\section{Estimation of Departure Profile}

The input-output technique uses the start-up lost time, saturation headway, and phase change data to estimate the departure profile. Figure $3 \mathrm{c}$ shows the departure profile estimate for this technique. The trend line shown indicates that the signal indication is red until time $t=45 \mathrm{~s}$. At this time, the signal indication changes to green; however, departures do not occur until time $t=47 \mathrm{~s}$ because of a 2.0-s start-up lost time. The departure profile is estimated only until the queue is discharged. The smooth line in Figure $3 \mathrm{c}$ represents the fact that the departure profile is a calculated projection, not a real-time estimate. The slope of the departure profile from time $t=47 \mathrm{~s}$ to $t=$ $55 \mathrm{~s}$ equals the input saturation headway.

Figure $3 \mathrm{~d}$ shows the departure profile for the hybrid technique. This departure profile is measured in real time by using the count detector at the stop bar and represents a more accurate representation of the departure profile for the current signal cycle. This additional measurement is the fundamental difference between the two techniques.

\section{Delay and Queue Estimation with Queue Polygon}

A queue polygon is obtained by superimposing the departure and arrival profiles. The area within the polygon is the total delay incurred by vehicles for that cycle. The curve that defines the polygon indicates the number of vehicles in queue at any time in the cycle. Thus, maximum queue length can be obtained from the queue polygon by finding the ordinate at the start of the green plus start-up lost time. Figure $3 e$ and illustrate the queue polygons obtained with the input-output and hybrid 


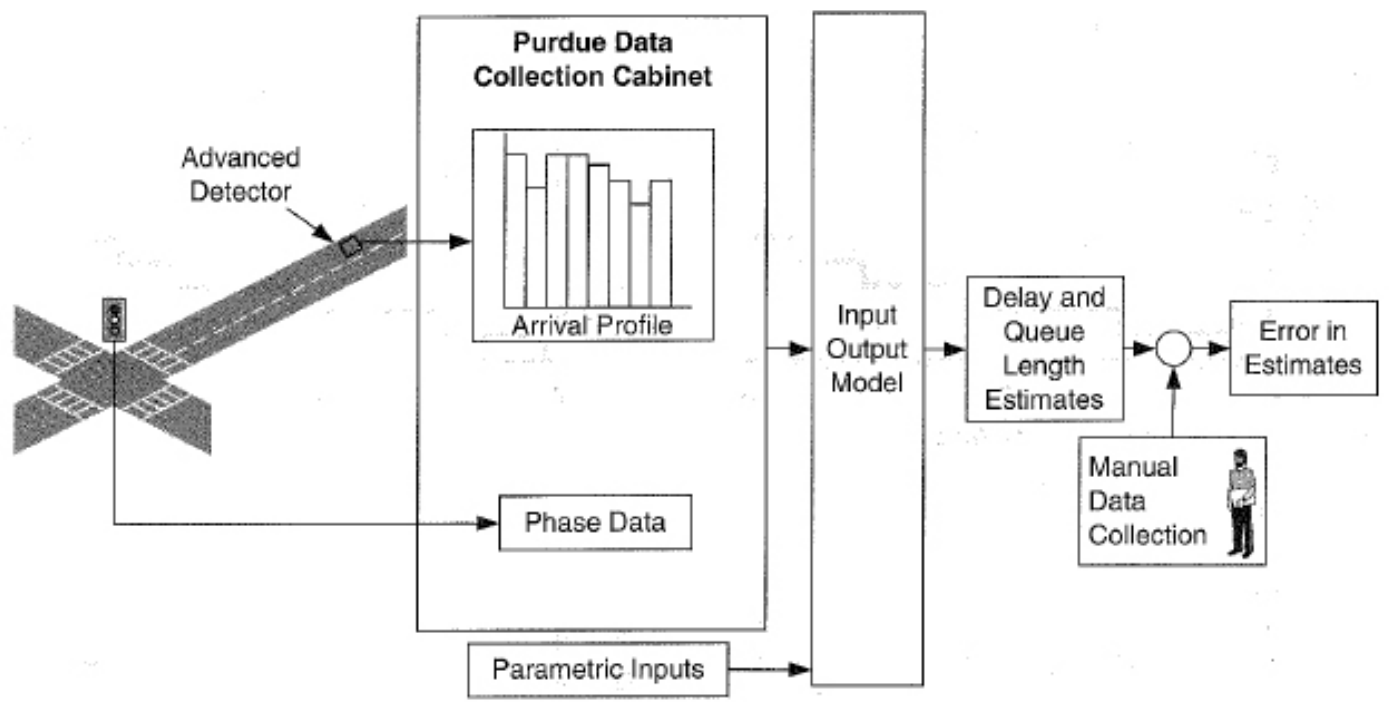

(a)

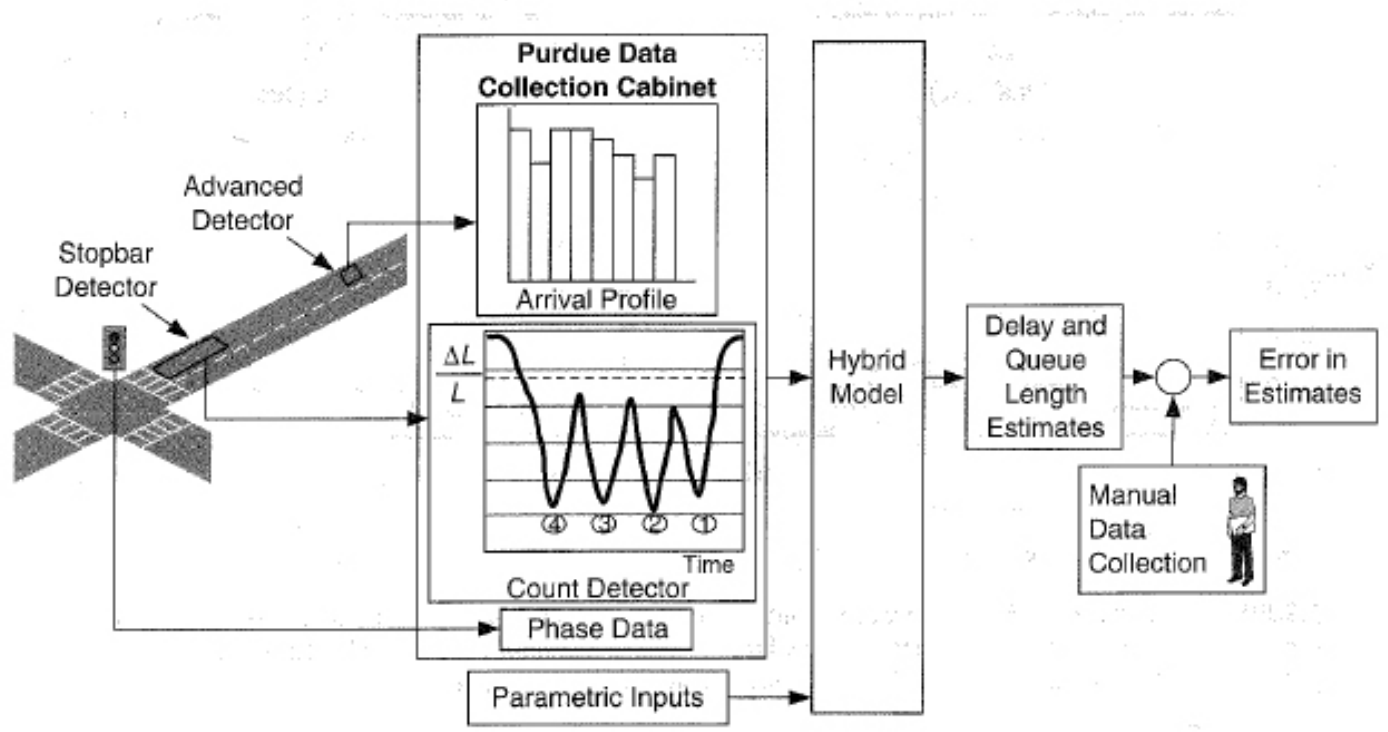

(b)

FIGURE 2 Real-time delay estimation techniques: $(\theta)$ input-output technique and $(b)$ hybrid technique.

techniques, respectively.

Figure $3 e$ indicates that the queue length is one vehicle from time $t=3 \mathrm{~s}$ to $\mathrm{t}=18 \mathrm{~s}$; it increases to two vehicles at that time and remains at two vehicles until time $t=39 \mathrm{~s}$. The maximum queue of three vehicles occurs from $t=39$ $\mathrm{s}$ to $\mathrm{t}=47 \mathrm{~s}$. The area under the polygon can be computed as 89 veh-s total delay. When divided by the six vehicle arrivals during the cycle, the average delay is computed as $14.8 \mathrm{~s}(=89 / 6)$. The first vehicle to arrive at $\mathrm{t}=3 \mathrm{~s}$ did not depart until $\mathrm{t}=48 \mathrm{~s}$; hence, it incurred a maximum delay of $45 \mathrm{~s}$.

\section{FUNCTIONAL REQUIREMENTS}

The estimate of delay and queue length for an approach was calculated for each lane for each cycle. Table 1 gives the parametric input data required by each of the two techniques. It can be seen from Table I that both techniques require a set of common parametric inputs. How- ever, there are three differences in the input data provided to the techniques:

- Start-up lost time and saturation headway are primary inputs only for the input-output technique. They are used to estimate the departure profile. In the hybrid technique, the start-up lost time and saturation headway would only be used when the count detector is positioned at some distance before the stop bar and records some actuation before the phase turns green. These vehicles are then assumed to start discharging after start-up lost time with the saturation headway.

- Queue clearance headway is used only in the hybrid technique to determine when the standing queue has been discharged.

Both the input-output technique and the hybrid technique are composed of three modules: arrival profile, departure profile, and delay estimation. 


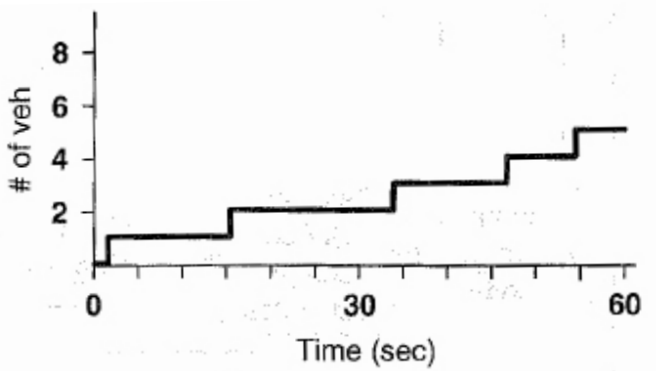

(a)

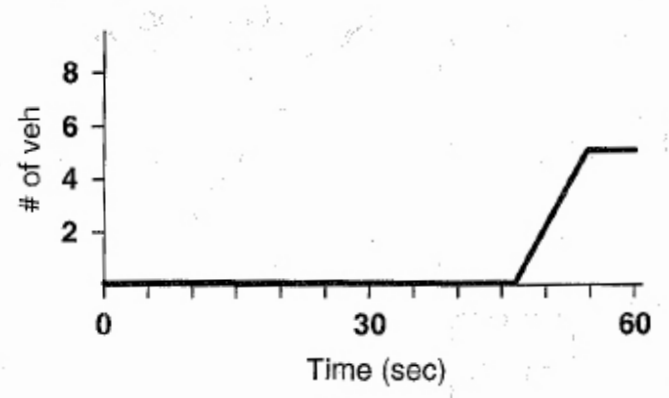

(c)

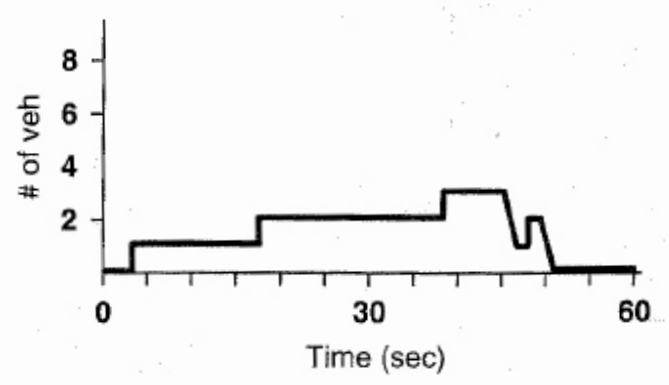

(e)

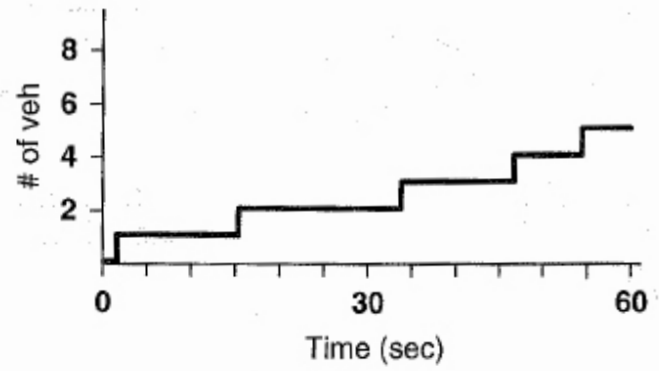

(b)

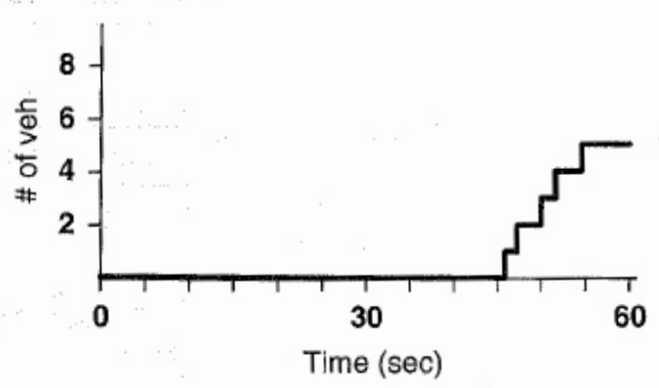

(d)

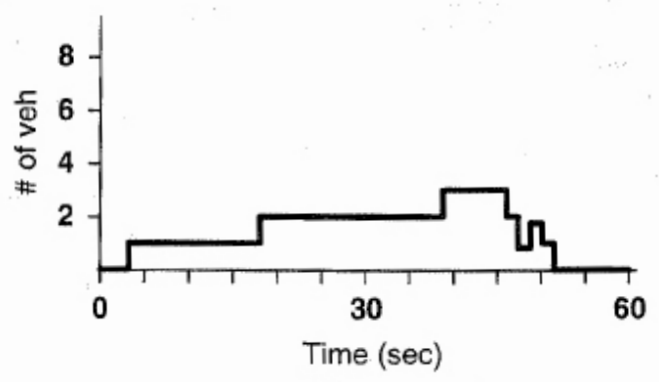

(f)

FIGURE 3 Comparison of delay measurement techniques: [a] input-output arrival profile, (b) hybrid arrival profile, $(c)$ input-output departure profile, (d) hybrid departure profile, (e) input-output queue profile for computing delay, and $(f)$ hybrid queus profile for computing delay.

TABLE 1 Parametric Input Used by Input-Output and Hybrid Techniques

\begin{tabular}{|c|c|c|c|}
\hline Input Parameter & $\begin{array}{l}\text { Input-Output } \\
\text { Technique }\end{array}$ & $\begin{array}{l}\text { Hybrid } \\
\text { Technique }\end{array}$ & Description \\
\hline Arrival shift & Primary & Primary & $\begin{array}{l}\text { Time taken for free flowing vehicle to travel from advance } \\
\text { detector to stop bar. This value is added to advance detector } \\
\text { actuations to estimate the time a vehicle reaches the stop } \\
\text { bar under free flowing conditions. }\end{array}$ \\
\hline Start-up lost time & Primary & Backup & $\begin{array}{l}\text { Additional time consumed by the first few vehicles in a queue } \\
\text { at a signalized intersection beyond saturation headway (7). }\end{array}$ \\
\hline Storage capacity & Primary & Primary & $\begin{array}{l}\text { Maximum numbers of vehicles that can be stored per lane } \\
\text { before the queue spills back over the advance detectors. }\end{array}$ \\
\hline Saturation headway & Primary & Backup & $\begin{array}{l}\text { Headway at which standing queue is discharged after start-up } \\
\text { lost time. }\end{array}$ \\
\hline $\begin{array}{l}\text { Queue clearance } \\
\text { headway }\end{array}$ & Not used & Primary & $\begin{array}{l}\text { Upper limit of saturation flow headway. If a headway greater } \\
\text { than or equal to queve clearance headway is detected then } \\
\text { queue is assumed to be discharged. }\end{array}$ \\
\hline
\end{tabular}




\section{Arrival Profile Module}

Figure 4 shows the common module used for estimating the arrival flow profile and maximum queue length for a given cycle. The step-by-step description of this module follows the flowchart in Figure 4 (from top to bottom):

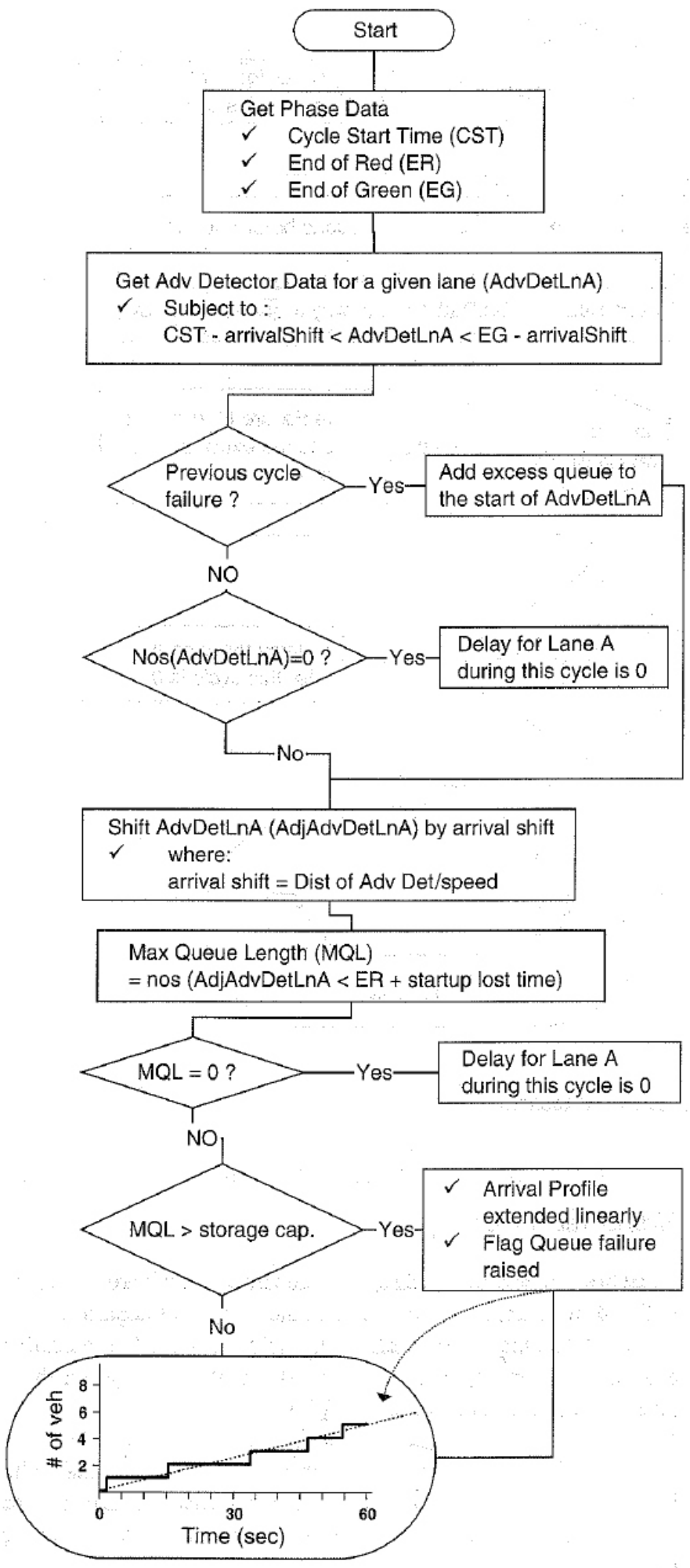

FIGURE 4 Arrival profile module (common to both input-output and hybrid techniques].
1. The phase change data (cycle start time, end of red, end of green) are obtained for a given cycle.

2 . The advance detector actuations that occur between the cycle start time minus arrival shift and the end of green minusarrivalshiftarecontinuously obtained as they occur.

3. When oversaturated conditions occur, the overflow queue from the previous cycle is added to the start of the arrival profile for the current cycle.

4. In the absence of any advance detector actuations, zero total delay and zero maximum queue length are recorded and the statistical analysis for the cycle is terminated.

5. An amount equal to the arrival shift time is added to each vehicle's time of arrival at the advance detectors. This adjustment is needed to shift the arrival time to the advance detector to the arrival time to the stop bar.

6. Maximum queue length is obtained by counting the number of advance detector actuations before the end of red plus start-up lost time. This maximum queue length is recorded for each lane per cycle.

7. If there is no standing queue at the end of the red, the delay for the subject traffic lane is recorded as zero and the statistical analysis for this cycle is terminated.

8. If the maximum queue length for a given cycle is equal to or greater than the storage capacity for that lane, a queue failure flag is set and the arrival profile is linearly extrapolated from this point to the end of the cycle. The linear extrapolation is based on the historic arrival flow rate before queue spillback.

9. The output from this module is the arrival time of each vehicle at the stop bar assuming a free-flow condition.

\section{Departure Profile Module}

Figure 5 shows the module used for estimating the departure flow profile. The step-by-step description of this module follows the flow chart in Figure 5.

\section{Input-Output Technique}

1. The queue is discharged at the input saturation headway after the end of the red plus start-up lost time.

2 . If the queue is not completely discharged by the end of the green, a cycle failure flag is set and the number of excess vehicles remaining in queue is recorded. This value is subsequently used as an overflow queue in the arrival profile module for the next cycle.

\section{Hybrid Technique}

1. Stop bar detector actuations between the start and end of the green are obtained.

2. If the stop bar detector actuations are zero for the cycle, zero delay and zero maximum queue length are recorded for this cycle and the process is terminated.

3. The queue clearance time is obtained by finding the first headway greater than the queue clearance headway. All the actuations before queue clearance time are used for delay estimation.

4. If the queue is not completely discharged by the end of the green, a cycle failure flag is set and the number of excess vehicles remaining in queue is recorded. This value is subsequently used as an overflow queue in the arrival profile module for the next cycle. 

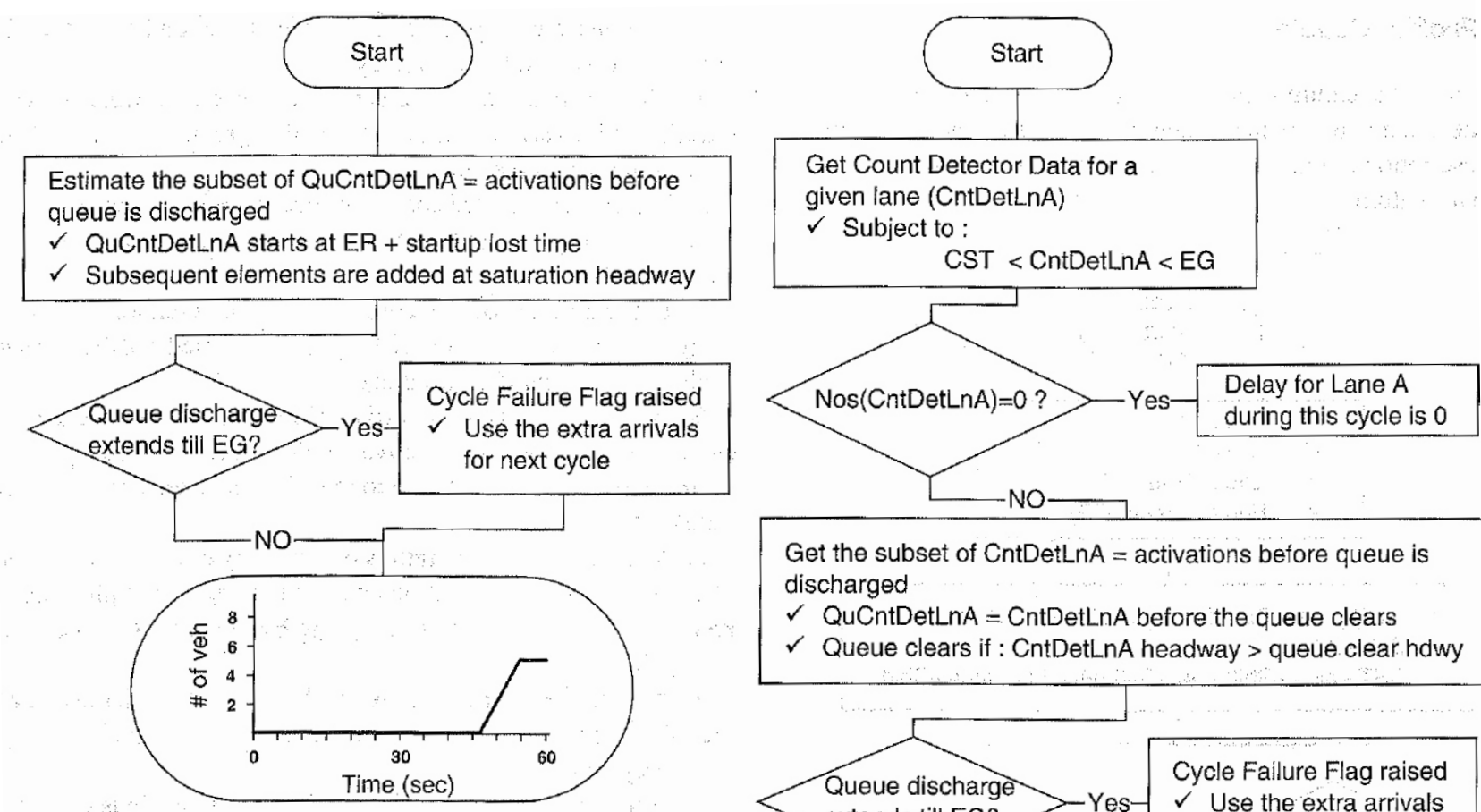

Get the subset of CntDetLnA = activations before queue is discharged

$\checkmark$ QuCntDetLnA $=$ CntDetLnA before the queue clears

$\checkmark$ Queue clears if : CntDetLnA headway > queue clear hdwy
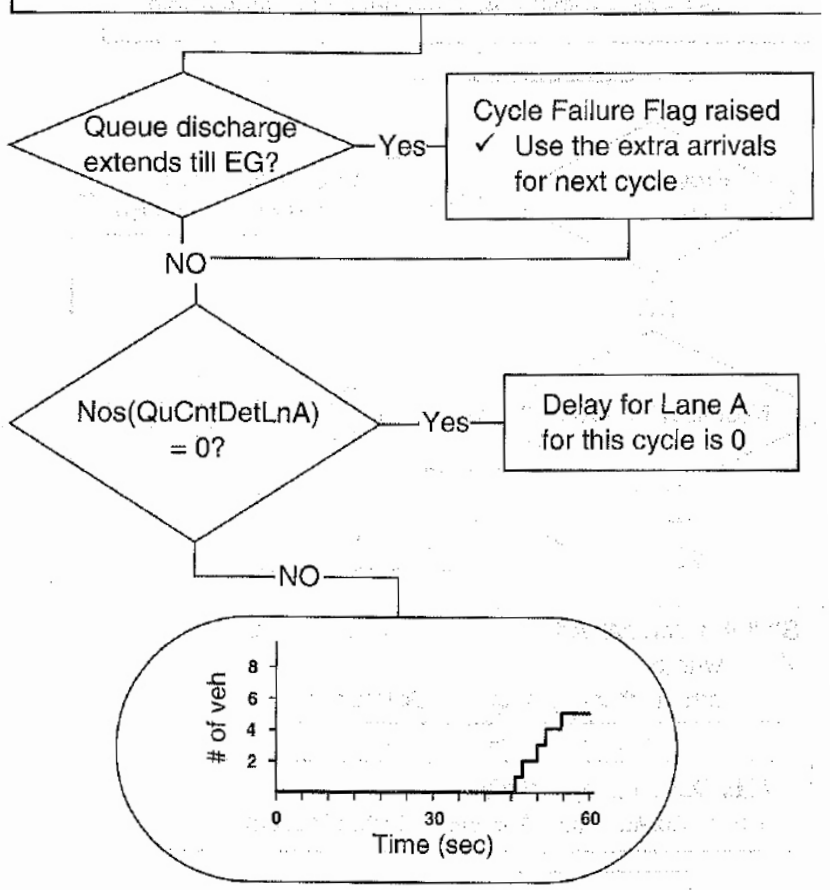

(a)

(b)

FIGURE 5 Departure profile modules: (a) input-output technique and $(b)$ hybrid tectinique.

\section{Delay Estimation Module}

Figure 6 shows the module used for estimating delay by using the arrival profile and departure profile generated in the previous modules. The step-by-step description of this module follows the flowchart in Figure 6.

\section{Input-Output Technique}

Total delay is the difference between the departure and arrival profiles. The average delay per cycle for each lane is calculated by dividing the total delay by the total number of arrivals during that cycle.

Hybrid Technique

Since both the arrival profile and the departure profile are generated with real-time data, it is possible that the number of departures and arrivals do not match. Errorchecking logic is provided to detect this condition and ensure accurate delay estimates. This logic for three possible scenarios is described as follows:

Case 1. Number of arrivals $=$ number of departures. This is the ideal scenario in which it is assumed that no sensor disturbances or lane changes occur and delay can be directly estimated by subtracting departure time from arrival time.

Case 2. Number of arrivals $>$ number of departures. This case might be due to false calls on the advance detector or to vehicles exiting the subject lane after cross 


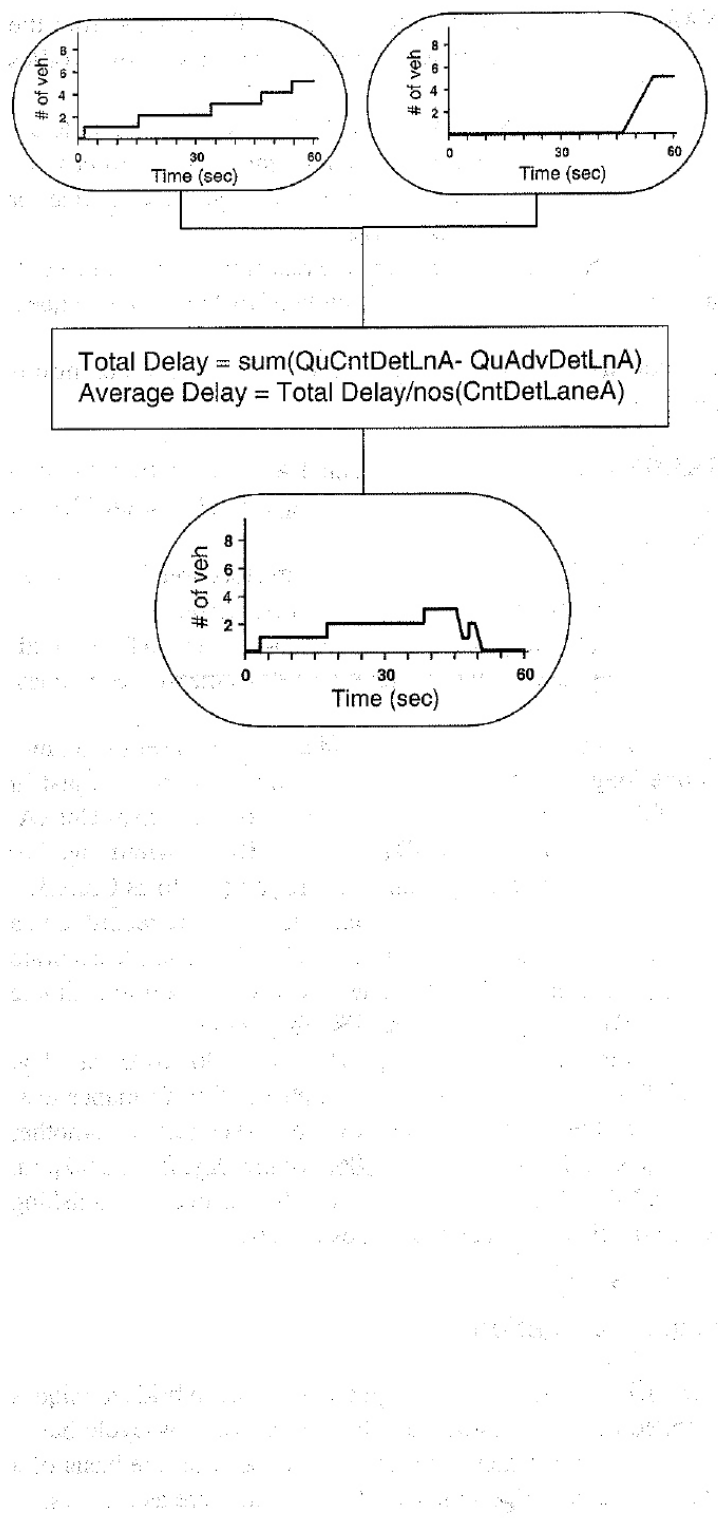

(a)
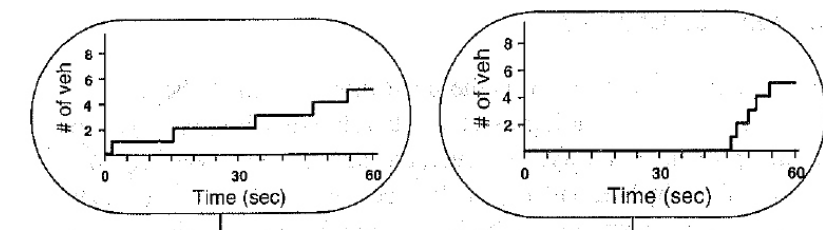

Get the subset of AdjAdvDetLnA = activations before queue is discharged $\checkmark$ QuAdvDetLnA $=$ AdjAdvDetLnA before the queue clears
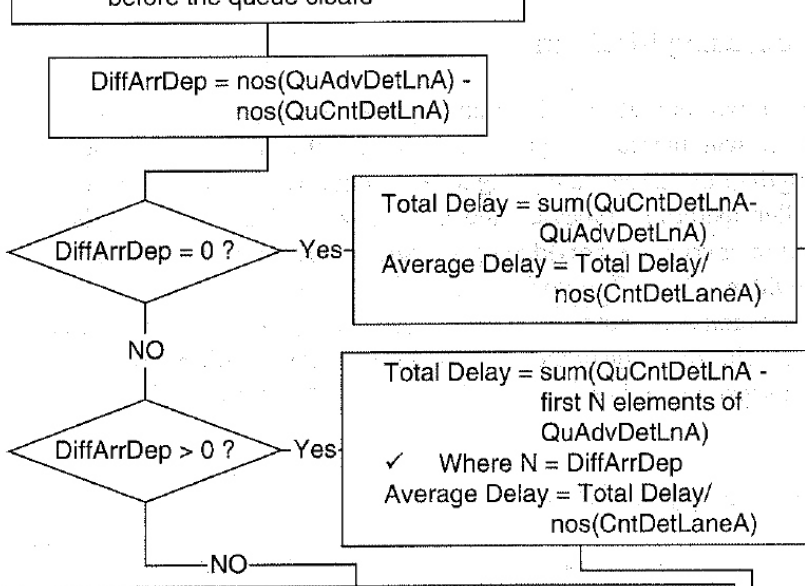

Total Delay $=\operatorname{sum}($ QuCntDetLnA- [Nelements; QuAdvDetLnA])

$\checkmark \quad$ Where $N=$ DiffArrDep

$\checkmark$ Add $N$ element in arrivals at the start of the cycle

Average Delay $=$ Total Delay/nos $($ CntDetLaneA $)$

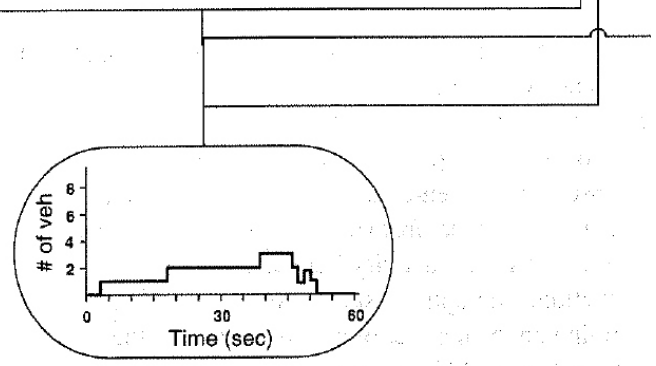

(b)

FIGURE 6 Delay estimation modules: (a) input-output technique and $[b]$ hybrid technique.

ing the advance detector. In this scenario, a vehicle excess is computed (= arrivals minus departures) and then subtracted from the back of the queue. Removing these phantom vehicles from the back of the queue will yield a conservatively high estimate of delay.

Case 3. Number of arrivals $<$ number of departures. This case might be due to missed calls on the advance detector or to vehicles entering the subject lane after crossing the advance detector. In this scenario, a vehicle deficiency is computed (= departures minus arrivals) and then added to the arrival flow profile. These vehicles are added to the profile as if they arrived at the start of the red. This approach will yield a conservatively high estimate of delay.
The corrections described in Cases 2 and 3 are based on the assumption that the stop bar detector yields an accurate estimate of departures. This assumption is made because the likelihood of lane changes closer to the stop bar detector is small in case of false calls by the stop bar detector, the hybrid technique will give a higher (conservative) estimate of delay.

\section{TECHNOLOGY REQUIREMENTS}

The hardware requirements of both techniques are similar except that the hybrid technique requires an extra set of count detectors at the stop bar. 


\section{Sensor Requirements}

The inductive loop detector is the most likely sensor to be used to implement these technologies given its relatively low installation cost and proven reliability. However, any sensor that can count individual vehicles by lane with reasonable accuracy can be used. A recent review of sensor performance by Martin and Feng (10) indicates that magnetic, true-presence microwave, Doppler microwave, and video image vehicle detection system (VIVDS) detectors are also suitable for all-weather applications on urban street segments. However, research by Rhodes et al. (11) questions the use of VIVDS.

\section{Processing Platform}

The input-output technique and hybrid technique could be integrated with the traffic signal controller if realtime delay and queue length information were going to be used to dynamically adapt controller operation. Either technique could be provided as a controller option or could be provided as a separate module. Either technique would need the detector inputs and phase inputs to process the delays and maximum queue length on a cycleby-cycle basis. In this research, collection of the phase status and detector information was in a separate module.

\section{Technology Limitations}

Both input-output and hybrid techniques require a set of advance detectors for measuring the arrival profile. The sensors should be located sufficiently far back from the intersection to avoid frequent spillback of queues past the sensor. The sensor will not be able to accurately count vehicle arrivals if the queue backs over the advance detectors. On the basis of typical cycle durations and peak-hour flow rates, the location of this sensor would likely be 400 feet or more in advance of the intersection. However, the sensor should not be located so distant from the intersection that driveway activity between the sensor and the stop bar degrades the accuracy of the predicted arrival flow profile. This objective is often in conflict with the desire to locate the sensor back far enough to avoid queue spillback. In general, the farther the sensors are from the intersection, the more likely there will be mid-block traffic activity between the advance detector and the intersection. The optimal sensor location will vary from site to site depending on the number of access points and their traffic volume.

The hybrid technique also needs a set of count detectors at the stop bar for real-time estimation of discharge profiles. If the performance of the stop bar count detector is poor so that inaccurate counts are provided, the hybrid technique might not perform as well as the input-output technique.

\section{CALIBRATION TECHNIQUE \\ Data Collection Procedure}

Figure 7 shows the data collection site, located at the signalized intersection of SR-37 and SR-38 in Noblesville, Indiana. This is an extensively instrumented intersection with the capability of collecting detector actuations, signal states, and simultaneous video recording of the existing traffic condition.

The detectors used for data collection for low-volume conditions include the following:
- NA8, NB8. Advance detectors located 405 feet away from the stop bar; these detectors were used for estimating arrival flow profiles for both techniques.

- NA1, NA2, NA3, NA4, NB1, NB2, NB3, NB4. Stop bar detectors used in combination with vehicle recognition logic to provide vehicle counts; these detectors were used in the hybrid technique for real-time estimation of lane discharge.

- C2N. Camera used for recording the real-time video for ground-truthing the delays and queue lengths estimated by the two techniques.

The detectors used for data collection for heavy-volume conditions include

- SA5, SB5. Advance detectors located 405 feet away from the stop bar; these detectors were used for estimating arrival flow profiles for both techniques.

- SA-M1, SA-M2. Stop bar microloop detectors use inthe hybrid technique for real-time estimation of lane discharge.

- C2S. Camera used for recording the real-time video for ground-truthing the delays and queue lengths estimated by the two techniques.

Stop Bar Detectors NA1 through NA4 are wired in series to function as one long detection zone in the inside through lane, just in advance of the stop bar. This detection zone is referred to as CntNA. Similarly, Stop Bar Detectors NB1 through NB4 are wired together to monitor the outside through lane and are referred to as CntNB.

The detector actuations and phase change data were recorded in a data file. These data have a resolution of $1 / 1,000$ $\mathrm{s}$ and are accurate to within approximately $1 / 100 \mathrm{~s}$. These data were used to estimate the arrival and discharge profiles as described earlier.

Four hours of data were collected on October 30, 2005, Sunday, from 7:00 a.m. to 11:00 a.m. for the first phase of performance testing, which used the techniques under lowvolume conditions. Another $4 \mathrm{~h}$ of data were collected June 21, 2006, Wednesday, from 2:00 p.m. to 6:00 p.m. Video feeds were also recorded for manually establishing groundtruth delay and queue length estimates.

\section{Technique Application}

After the data were collected, the input-output and hybrid techniques were applied offline to estimate delays on a cycle-by-cycle basis. The values of the parametric inputs were chosen on the basis of a preliminary site investigation. The chosen values are as follows:

Parametric input for input-output technique:

- Arrival shift $=\frac{405 \mathrm{ft}}{81 \mathrm{ft} / \mathrm{s}}=5 \mathrm{~s}$,

- Start-up lost time = $4 \mathrm{~s}$,

- Storage capacity = 14 cars per lane,

- Saturation headway $=2 \mathrm{~s}$.

Parametric input for hybrid technique:

- Arrival shift = $5 \mathrm{~s}$,

- Start-up lost time $=4 \mathrm{~s}$,

- Storage capacity: 14 cars per lane,

- Saturation headway = $2 \mathrm{~s}$,

- Queue clearance headway $=4 \mathrm{~s}$. 


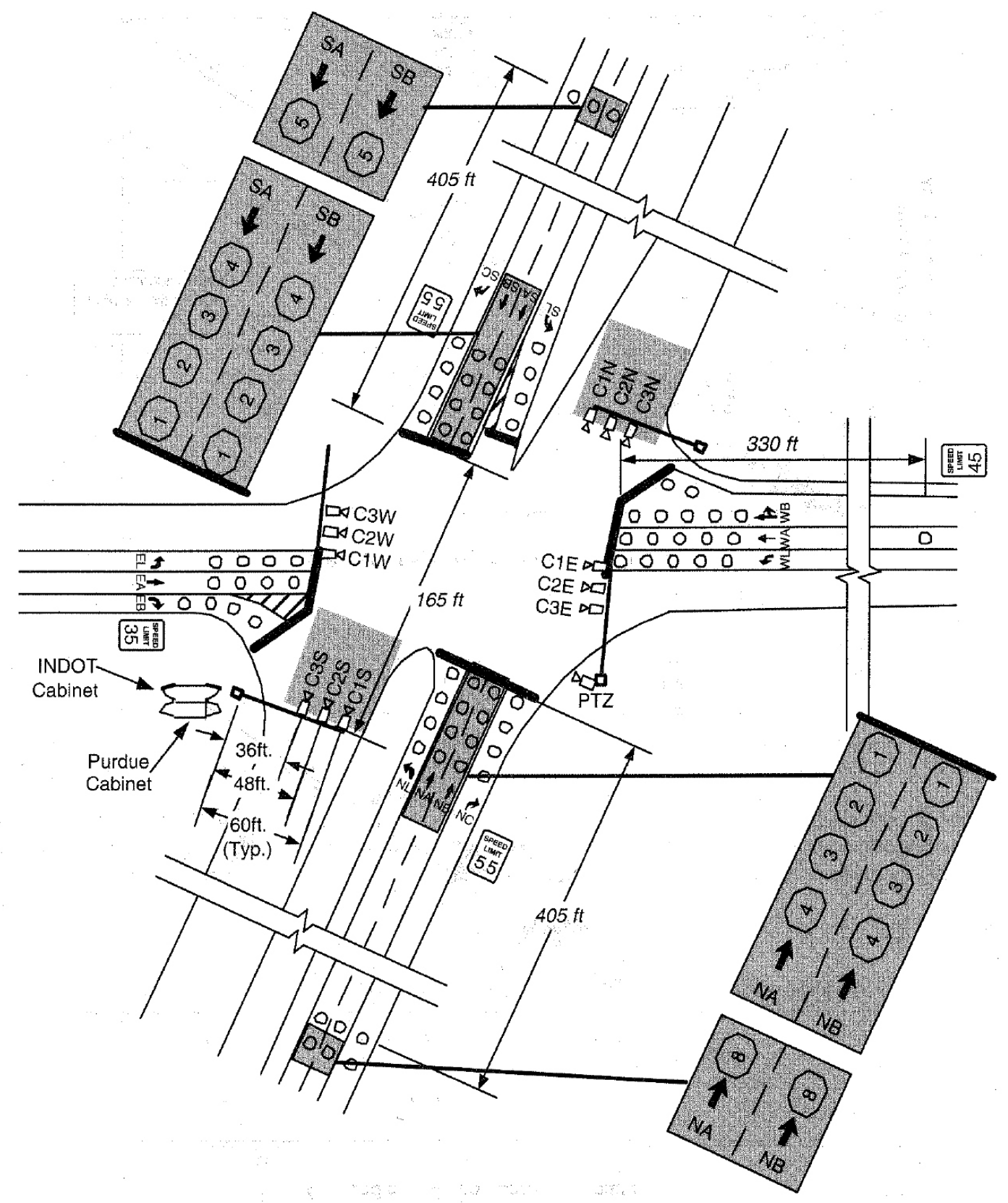

FIGURE 7 Data collection site at Noblesville.

The input-output technique and hybrid technique, as described in a previous section, were then applied offline to the collected data to obtain the maximum queue length and approach delay estimate for each cycle in the 4-hour period.

\section{Manual Measurement of Delay and Maximum Queue Length from Video Recording}

Traffic events on the intersection approach were recorded during the study period with Camera C2N (Figure 7) and Camera C2S. The video recording was used to quantify ground-truth vehicle arrival times and departure times as well as the delay and maximum queue length for each cycle. These data were then used to evaluate the accuracy of both techniques.

\section{RESULTS}

The performance of the input-output and hybrid techniques was evaluated on a cycle-by-cycle basis. A total of 147 cycles were analyzed for the first phase of the 4-hour study period, and 122 cycles were evaluated for the second phase. The total through volume varied from $115 \mathrm{vph}$ to $490 \mathrm{vph}$ during the first phase of the study, whereas it ranged from $435 \mathrm{vph}$ to $820 \mathrm{vph}$ during the second phase. Figure 8 compares the estimated and true value of the average delay during low-volume and heavy-volume conditions with a scatter plot of delay estimates from the hybrid and the input-output techniques. The solid line represents the ground truth where the estimated average delay value equals the true value of the delay. 


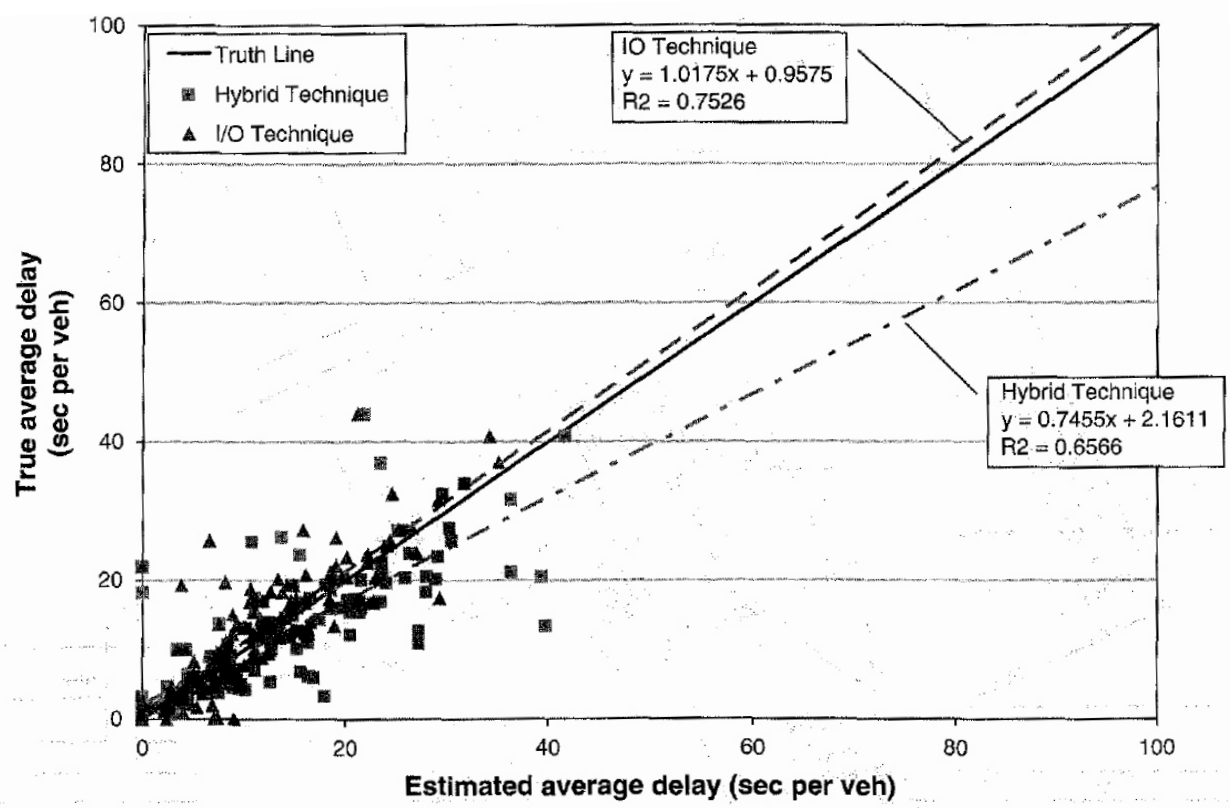

(a)

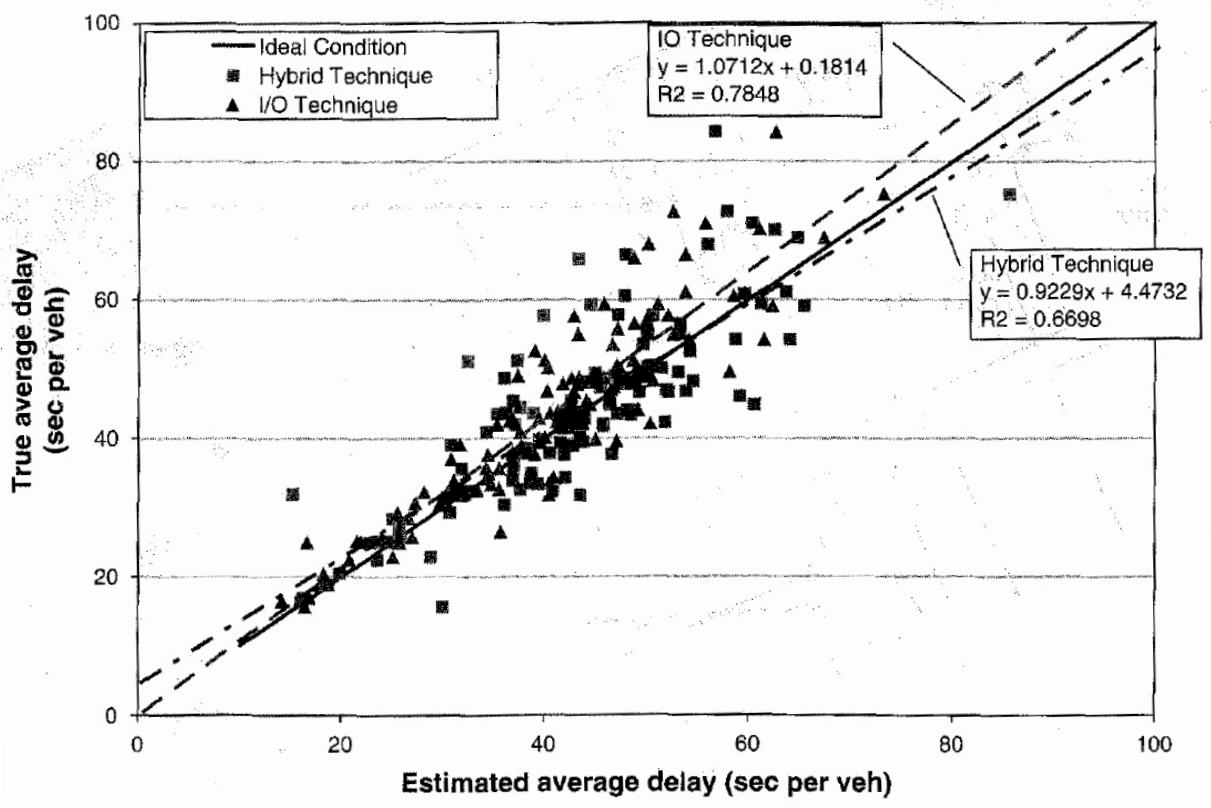

(b)

FIGURE 8 Comparison of estimated and true average delays, cycle-by-cycle evaluation: $(a)$ low-volume conditions and $[b]$ heavy-volume conditions.

The plot also shows the trend line fitted to the scatter plot for both techniques.

The slope of the trend line for the input-output approach was 1.0175 and 1.0712 during low-volume conditions and heavy-volume conditions, respectively, which is not significantly different from 1.0. A slope of 1.0 suggests that error is not a function of estimated average delay. The intercept coefficient is 0.96 for low-volume conditions and 0.18 for heavy volumes. These coefficients indicate that a small bias exists in the estimation of average delay. For practical applications this bias is probably too small to be of concern.
The results for the hybrid technique were not as good as those for the input-output technique in spite of more input information. The main reason for this poor performance was that the input noise of the stop bar count detector degraded the overall performance of the hybrid technique.

In addition, the study site had long left-turn and rightturn bays, thus reducing the percentage of left-turning and right-turning vehicles in the through-vehicle stream detected at the advance detector. The unavailability of long turn bays might degrade the performance of the input-output technique significantly. 
TABLE 2 Comparison of Input-Output and Hybrid Techniques, 15-min Summary, Low Volume

\begin{tabular}{|c|c|c|c|c|c|c|c|c|}
\hline \multirow{3}{*}{$\begin{array}{l}\text { Start Time } \\
\text { (Sunday) }\end{array}$} & \multirow{3}{*}{$\begin{array}{l}\text { End Time } \\
\text { (Sunday) }\end{array}$} & \multicolumn{4}{|c|}{ Average Max. Queue Length } & \multirow{2}{*}{\multicolumn{3}{|c|}{ Average Delay (s/veh) }} \\
\hline & & \multicolumn{2}{|l|}{ NA } & \multicolumn{2}{|l|}{ NB } & & & \\
\hline & & True & Error & True & Error & True & $\begin{array}{l}\text { Input-Output } \\
\text { Error }\end{array}$ & $\begin{array}{l}\text { Hybrid } \\
\text { Error }\end{array}$ \\
\hline 7:00 a.m. & $7: 14$ a.m. & 1.2 & 0.0 & 0.7 & 0.2 & 13.4 & -0.3 & 2.6 \\
\hline $7: 15$ a.m. & 7:29 a.m. & 0.6 & 0.1 & 0.8 & 0.0 & 9.4 & 0.1 & 4.6 \\
\hline 7:30 a.m. & 7:44 a.m. & 1.0 & 0.3 & 0.4 & 0.1 & 14.0 & -2.0 & -2.4 \\
\hline 7:45 a.m. & 7:59 a.m. & 0.4 & -0.3 & 0.3 & 0.1 & 5.5 & 0.6 & 1.8 \\
\hline 8:00 a.m. & $8: 14$ a.m. & 1.0 & 0.1 & 1.3 & 0.6 & 14.4 & -1.0 & 2.3 \\
\hline $8: 15$ a.m. & $8: 29$ a.m. & 0.6 & 0.0 & 0.7 & 0.2 & 8.5 & 0.7 & 3.3 \\
\hline $8: 30$ a.m. & 8:44 a.m. & 1.3 & -0.2 & 1.0 & 0.1 & 12.2 & 1.5 & -1.1 \\
\hline $8: 45$ a.m. & 8:59 a.m. & 1.3 & 0.1 & 0.9 & 0.1 & 6.9 & 0.1 & 0.7 \\
\hline 9:00 a.m. & $9: 14$ a.m. & 0.8 & -0.4 & 0.6 & 0.2 & 7.6 & -2.6 & -1.0 \\
\hline $9: 15 \mathrm{a} . \mathrm{m}$. & 9:29 a.m. & 1.2 & -0.1 & 1.3 & 0.0 & 9.8 & -3.9 & 0.1 \\
\hline $9: 30$ a.m. & 9:44 a.m. & 1.5 & -0.4 & 0.7 & 0.5 & 7.6 & -1.0 & -0.7 \\
\hline $9: 45$ a.m. & 9:59 a.m. & 0.9 & 0.1 & 1.0 & 0.2 & 6.6 & -0.1 & 3.8 \\
\hline 10:00 a.m. & 10:14 a.m. & 2.1 & -0.1 & 1.9 & 0.3 & 13.3 & -2.7 & 1.3 \\
\hline 10:15 a.m. & 10:29 a.m. & 2.6 & 0.4 & 2.0 & 0.4 & 15.7 & -0.8 & 0.2 \\
\hline $10: 30$ a.m. & 10:44 a.m. & 2.8 & 0.0 & 2.4 & 0.1 & 18.3 & -4.3 & $\therefore \quad 0.2$ \\
\hline 10:45 a.m. & 10.59 a.m. & 2.7 & -0.4 & 2.7 & 0.4 & 18.6 & -2.8 & -0.1 \\
\hline
\end{tabular}

Tables 2 and 3 give the average delay and maximum queue length estimated by using the input-output and hybrid techniques, averaged over a 15-minute period, for low-volume and heavy-volume conditions, respectively.

The average root mean square error (RMSE) for the input-output technique in measuring average delay per cycle was $0.4 \mathrm{~s}$ during low volume and $0.6 \mathrm{~s}$ during heavy- volume conditions. The RMSE for the hybrid approach in measuring average delay per cycle was $0.5 \mathrm{~s}$ for low-volume conditions and $0.7 \mathrm{~s}$ for the second phase, heavyvolume conditions.

The average RMSE for the input-output technique in measuring average maximum queue length per cycle during low-volume conditions was in the range of 0.06 vehicle and during the second phase it was close to 0.15 vehicle.

TABLE 3 Comparison of Input-Output and Hybrid Techniques, 15-min Summary, Heavy Volume

\begin{tabular}{|c|c|c|c|c|c|c|c|c|}
\hline \multirow[b]{3}{*}{$\begin{array}{l}\text { Start Time } \\
\text { (Sunday) }\end{array}$} & \multirow[b]{3}{*}{$\begin{array}{l}\text { End Time } \\
\text { (Sunday) }\end{array}$} & \multicolumn{4}{|c|}{ Average Max. Queue Length } & \multirow{2}{*}{\multicolumn{3}{|c|}{ Average Delay (s/veh) }} \\
\hline & & \multicolumn{2}{|l|}{ SA } & \multicolumn{2}{|l|}{ SB } & & & \\
\hline & & True & Error & True & Error & True & $\begin{array}{l}\text { Input-Output } \\
\text { Error }\end{array}$ & $\begin{array}{l}\text { Hybrid } \\
\text { Error }\end{array}$ \\
\hline 2:00 p.m. & $2: 14$ p.m. & 8.1 & -1.0 & 7.3 & 0.8 & 41.3 & -3.2 & -1.7 \\
\hline $2: 15$ p.m. & 2:29 p.m. & 4.6 & -0.6 & 6.3 & 0.0 & 37.7 & -2.3 & 0.8 \\
\hline 2:30 p.m. & 2:44 p.m. & 6.1 & -0.6 & 5.3 & 0.4 & 35.5 & 0.2 & 6.0 \\
\hline $2: 45$ p.m. & 2:59 p.m. & 7.6 & -0.9 & 6.3 & 0.3 & 42.4 & -1.3 & 3.1 \\
\hline 3:00 p.m. & $3: 14$ p.m. & 10.0 & -0.9 & 8.0 & -0.1 & 41.3 & -0.3 & 1.7 \\
\hline 3:15 p.m. & 3:29 p.m. & 11.4 & -0.7 & 9.0 & 0.3 & 45.5 & 0.3 & 3.7 \\
\hline $3: 30$ p.m. & 3:44 p.m. & 11.4 & 0.0 & 8.3 & 0.1 & 50.4 & -6.6 & -5.2 \\
\hline 3:45 p.m. & 3:59 p.m. & 8.6 & -0.9 & 7.7 & 0.4 & 43.0 & -3.3 & 0.2 \\
\hline 4:00 p.m. & 4:14 p.m. & 10.1 & 0.1 & 7.5 & -0.1 & 46.2 & -4.3 & -3.5 \\
\hline 4:15 p.m. & 4:29 p.m. & 9.3 & 0.9 & 8.3 & 0.4 & 39.7 & -1.3 & -3.2 \\
\hline 4:30 p.m. & 4:44 p.m. & 10.4 & -0.3 & 9.4 & -0.7 & 41.9 & -1.7 & -1.7 \\
\hline 4:45 p.m. & 4:59 p.m. & 10.6 & -0.7 & 9.6 & 0.3 & 42.8 & -1.4 & -1.1 \\
\hline 5:00 p.m. & 5:14 p.m. & 12.0 & -0.3 & 10.0 & -0.6 & 51.9 & -5.5 & -1.7 \\
\hline 5:15 p.m. & 5:29 p.m. & 13.0 & -0.9 & 10.3 & -1.0 & 52.9 & -9.2 & -7.7 \\
\hline $5: 30$ p.m. & 5:44 p.m. & 8.0 & 0.0 & 8.4 & -0.3 & 35.7 & -0.2 & -1.2 \\
\hline 5:45 p.m. & 5:59 p.m. & 10.7 & -0.9 & 9.7 & 1.1 & 52.5 & -5.5 & -2.9 \\
\hline
\end{tabular}




\section{CONCLUSIONS AND RECOMMENDATIONS}

The input-output and hybrid measurement techniques perform satisfactorily in terms of estimation accuracy and-can be implemented in the field for real-time measurement of delay and maximum queue length. The choice of one technique over the other would be governed primarily by geometric conditions and the existing array of available vehicle sensors at the subject intersection.

The input-output technique is less costly and should be the first choice for the traffic engineer unless some special conditions exist to justify the higher cost of the hybrid technique. The hybrid technique might be beneficial for intersections with more inflow or outflow of traffic between the stop bar and the advance detector. Sites with huge variability in saturation flow rate (due to changing weather conditions) could gain substantially in the accuracy of the estimation by implementing the hybrid technique. The hybrid technique should also be considered if there are frequent queue spillbacks over the advance detector.

It can be expected that these techniques will be coded in the traffic controller. Traffic engineers can then choose a specific technique for evaluating intersection performance on the basis of site conditions.

\section{ACKNOWLEDGMENTS}

This work was supported in part by NCHRP and Purdue University. The materials and methods presented here were developed as part of NCHRP Project 3-79, Measuring and Predicting the Performance of Automobile Traffic on Urban Streets.

\section{REFERENCES}

1. Robertson, H. D. and W. G. Berger. A Manual Technique for Measuring Intersection Delay. Traffic Engineering and Control, 1976: 396-398.
2. Sofokidis, H., D. L. Tilles and D. R. Geiger. Evaluation of Intersection Delay Measurement Techniques. Highway Research Record 453, 1973: 28-47.

3. Powell, I. L. Field Measurement of Signalized Intersection Delay for 1997 Update of the Highway Capacity Manual. Transportation Research Record, No. 1646, 1998: 79-86.

4. Bonneson, J. A. Modeling Queued Driver Behavior at Signalized Junctions. Transportation Research Record, No. 1365, 1992: 99-107.

5. Son, Y. Queuing Delay Models for Two-Lane Highway Work Zones. Transportation Research, Vol. 33B, 1999: 459-471.

6. Dion, F., H. Rakha and Y. Kang. Comparison of Delay Estimates at Under-Saturated and Over-Saturated Pre-Timed Signalized Intersections. Transportation Research, Vol. 38B, 2004.

7. Highway Capacity Manual. Transportation Research Board, National Research Council, Washington, D.C., 2000.

8. Grenard, J., D. Bullock and A. P. Tarko. Evaluation of Selected Video Detection Systems at Signalized Intersections. Publication FHWA/IN/ JTRP-2001/22. Joint Transportation Research Program, Indiana Department of Transportation; Purdue University, 2001.

9. Smaglik, E. J. Enhanced Tactical and Strategic Control Methods for Traffic Signal Operation. Doctoral dissertation. West Lafayette, Ind.: Purdue University, 2005.

10. Martin, P. and Y. Feng. Detector Technology Evaluation. University of Utah, Salt Lake City, 2002.

11. Rhodes, A., D. M. Bullock, J. Sturdevant, Z. Clark and D. G. Candey, Jr. Evaluation of the Accuracy of Stop Bar Video Vehicle Detection at Signalized Intersections. Transportation Research Record: Journal of the Transportation Research Board, No. 1925, 2005: 134-145.

The contents of this paper reflect the views of the authors, who are responsible for the facts and the accuracy of the data presented, and do not necessarily reflect the official views or policies of the sponsoring organizations, nor do the contents constitute a standard, specification, or regulation.

The Traffic Signal Systems Committee sponsored publication of this paper. 